\title{
Cognitive functions in opioid-dependent males according to duration of abstinence
}

\author{
Buket Koparal ${ }^{1 \oplus}$, Ceyda Oktay Yanik $^{2 \oplus}$, Ismail Volkan Sahiner ${ }^{2}$, Hatice Ayca Kaloglu ${ }^{3}$, \\ Muhammed Hakan Aksu ${ }^{4}$, Cisem Utku ${ }^{5}$, Zehra Arikan ${ }^{5}$ \\ ${ }^{1}$ Recep Tayyip Erdogan University Training and Research Hospital, Department of Psychiatry, Rize - Turkey \\ ${ }^{2}$ Ankara Numune Training and Research Hospital, Department of Psychiatry, Ankara - Turkey \\ ${ }^{3}$ Ankara Diskapi Yildirim Beyazit Training and Research Hospital, Department of Psychiatry, Ankara - Turkey \\ ${ }^{4}$ Yildirim Beyazit University Yenimahalle Training and Research Hospital, Department of Psychiatry, Ankara - Turkey \\ ${ }^{5}$ Gazi University, Faculty of Medicine, Department of Psychiatry, Ankara - Turkey
}

\begin{abstract}
Objective: Opioid dependence is a neurobehavioral disorder characterized by repeated compulsive craving or using an opioid. In this study, we aimed to evaluate cognitive functions according to the duration of abstinence and other factors affecting cognitive functions.

Method: The study was carried out between February and April 2017 at the Psychiatry Department of Gazi University Medical Faculty. A total of 96 adult males participated; all of them had received detoxification treatment and were undergoing maintenance treatment. Patients were divided into three groups according to the duration of abstinence. First, a sociodemographic data form and Beck Anxiety Inventory were administered. Afterwards, the Wisconsin Card Sorting Test, Rey Auditory-Verbal Learning Test, and Stroop Test were applied.

Results: The sample group showed no significant impairment in their cognitive functions when compared to the norm values. The group of patients with 0-3 months of abstinence had higher memory scores than those who had been abstinent for more than 1 year. We also found that duration of multiple substance use, age of first substance use, and the number of treatments undergone affected some of the cognitive functions negatively.

Conclusion: This study is the first in which cognitive functions have been evaluated in opioid-dependent males in Turkey. It is not possible to control all of the factors affecting cognitive functions. Therefore, prospective studies and animal studies in which the effect of opioids can be examined exclusively are needed.
\end{abstract}

Keywords: Attention, cognitive functions, executive functions, memory, opioid dependence

\section{INTRODUCTION}

Opioid dependence primarily reflects a pattern of compulsive, prolonged self-administration of opioid substances with continuing use of opioids despite significant substance-related problems such as physiological, behavioral, and cognitive dysfunctions (1). Opioid use disorders are a growing public health problem. In Turkey, there were approximately 381.200 persons with substance use disorders in 1990; this number rose to 664.906 individuals in 2016 (2). In relation to the population, the rate increased from 0.0070

How to cite this article: Koparal B, Oktay Yanik C, Sahiner IV, Kaloglu HA, Aksu MH, Utku C, Arikan Z. Cognitive functions in opioid-dependent males according to duration of abstinence. Dusunen Adam The Journal of Psychiatry and Neurological Sciences 2020;33:50-58.

Correspondence: Buket Koparal, Recep Tayyip Erdogan University Training and Research Hospital, Department of Psychiatry, Rize - Turkey

Phone: +90 5356707861 E-mail: bkt_svnc@hotmail.com

Received: July 09, 2019; Revised: September 24, 2019; Accepted: November 07, 2019 
in 1990 to 0.0082 in 2016 (2). The size of the addiction problem globally becomes more apparent when considering that 1 out of every 10 persons with substance use has a substance use disorder or addiction (3).

Long-term opioid use leads to physical, mental, and social impairments as well as opioid-related increased death rates. In Turkey, 920 deaths due to substance use were reported in 2016 (2). Studies have shown that a decrease in the frequency and amount of opioid use leads to a decrease in criminal behavior and the risk of infection, while well-being from a psychosocial point of view increases $(4,5)$.

Cognitive functions generally include executive functions, attention, memory, and visual-spatial functions (6). Imagination, learning, memory, decisions-making ability, and conscience are also components of cognitive functions $(6,7)$. They have very important roles in the treatment of addiction, thought to affect not only the patients' mental performance but also treatment compliance and the course of the disease. Learning, retaining, and implementing new skills to prevent relapse, controlling impulsive responses and automatic thoughts, and developing problem-solving strategies are critical in adapting a new lifestyle and keeping away from substances (8-10).

Studies evaluating cognitive functions in opioid addicts are limited. Before taking up opioids, different substances usually have been used for a long time, with heroin typically being the last substance used. The number of studies investigating the effects of opioids on their own is limited (11-13). Some of the studies show that individuals with opioid dependence have impaired brain functions when compared to normal subjects. Dysfunction is particularly found in executive functions, including processing memory, planning, impulse control, and decision making $(8,14,15)$. In addition to studies reporting cognitive impairment being persistent in individuals with opioid dependence, there are others indicating that the disorder is due to the toxic effect of the substance and that cognitive functions return to normal after substance use is stopped (16-19). The methodological characteristics of the available studies limit the generalizability of the results.

In the literature review, no study was found investigating the relationship between opioid dependence and cognitive functions in Turkey. In this study, the aim was to evaluate the relationship between cognitive functions and duration of abstinence in opioid dependence and to investigate other factors affecting cognitive functions. We hypothesized that; 1 ) opioid- dependent patients have worse cognitive functions when compared to norm values of these tests, and 2) opioid-dependent patients with longer abstinence have better cognitive functions than patients with a shorter period of abstinence.

\section{METHOD}

\section{Participants}

The study was carried out at Gazi University Medical Faculty Hospital with male subjects between the ages of 15-40 who presented to the psychiatric outpatient clinic and who were diagnosed with opioid dependence according to ICD-10 diagnostic criteria. In Turkey, the ICD-10 medical classification system is used in procedural coding for the patient tracking system in all the hospitals and healthcare services, which is why we chose these criteria instead of DSM-5. All patients who were diagnosed as opioid-dependent were using heroin. Individuals with any drug use in the last 14 days, degenerative neurological disease, mental retardation, cerebral tumor or cerebrovascular disease, psychiatric comorbid illness except nicotine dependence (past and present), and persons who were illiterate were not included in the study. All participants enrolled in the study were given an informed consent form approved by Clinical Research Ethics Committee of the Gazi University Medical Faculty before clinical interviews and administration of the psychometric instruments. Detailed information was provided about the study and signed consent was obtained from all participants.

Ninety-six patients who agreed to participate in the study and who met the inclusion criteria were divided into 3 groups according to their self-reported period of abstinence: abstinent for between 0 and 3 months, abstinent for between 3 months and 1 year, and abstinent for more than 1 year.

No intelligence test was performed at the beginning of the study; patients who were considered mentally retarded clinically were excluded.

When the patient group was created, the patients' urine metabolite analyses were obtained and screened for substances in addition to the participants' selfreport.

A sociodemographic data form and Beck Anxiety Inventory (BAI) were administered before the neuropsychological test. Afterwards, within approximately 45 minutes, patients completed the Wisconsin Card Sorting Test (WCST), Rey AuditoryVerbal Learning Test (AVLT), and Stroop Test (ST). These tests are commonly used to evaluate cognitive 
functions in Turkey in general and also in our clinic. Most cognitive functions can be evaluated by these tests. We used BAI in order to compare participants' cognitive functions and anxiety scores. Even if they did not have an anxiety disorder, high anxiety levels could affect their performance scores.

The study did not include a control group; rather, the norm values of the BIL-NOT battery were used for comparison with normal individuals as a control group. The BIL-NOT battery is a data tool that includes norm values for some neurocognitive tests in Turkish samples (20).

\section{Measures}

Sociodemographic data form: This form, recording patients' sociodemographic characteristics, was prepared by the investigator.

Beck Anxiety Inventory (BDI): The scale developed by Beck (21) has been tested for validity and reliability in Turkish (22). The total score indicates the severity of anxiety experienced by the subject.

\section{Cognitive Assessment}

All participants were examined by one researcher who had attended a training course to ensure uniform procedures for administration and scoring.

After the clinical interview with the participants, AVLT, WCST, and ST were administered, taking approximately 45 minutes, to evaluate cognitive functioning. Validity-reliability studies for all tests had been carried out (23-25).

Stroop 5 indices were calculated for ST. This test evaluates selective attention as well as complex attention.

Four indices of WCST were calculated, including number of categories completed (CC), number of total errors, number of perseverative errors (PE), and number of non-PE (NPE). WCST evaluates complex attention, perseveration, working memory, and conceptualization.

Three indices of AVLT were calculated: Rey 1 for short-term memory, Rey 8 for long-term memory, and Rey 5 for auditory-verbal learning.

\section{Statistical Analysis}

Statistical evaluations were performed using SPSS version 15. Parametric tests were used for all evaluations. Descriptive analysis methods were used for the evaluation of sociodemographic data, t-test, chi-squared test, and one-way ANOVA were used for comparison between groups, and Pearson correlation analysis methods were used to examine the relationship between dependent variables. The Mann-Whitney $U$ test was used for comparison of the groups when the number of the persons included in the sample group was below 30 .

\section{RESULTS}

Participants' sociodemographic and clinical data are shown in Table 1.

Patients with opioid dependence were divided into three groups according to duration of abstinence. There was no significant difference between the groups regarding educational status $(\chi 2=1.409, \mathrm{p}=0.843)$, age (F2-95 $=0.100, \mathrm{p}=0.905)$, and income (F2-95 $=0.465$, $\mathrm{p}=0.630)$. There was significant difference between groups regarding employment status $(\mathrm{p}=0.01)$.

Information about the disease for the sample groups is given in Table 1 . There were no significant differences in duration of opioid use (F2-95 $=0.344, \mathrm{p}=0.710)$ and duration of multiple substance use (F2-95 $=0.541$, $\mathrm{p}=0.584$ ). All patients were receiving maintenance treatment with either naltrexone or buprenorphine/ naloxane. The doses are given in Table 1.

The sample groups were compared according to the clinical scales used; the results are shown in Table 2.

There was significant difference between the groups in Rey 8 Recall scores (F2-95=3.157, $\mathrm{p}<0.05$ ), while there was no significant difference between the groups in the other AVLT scores.

There was no significant difference between groups in ST scores and WCST scores ( $p>0.05)$.

Table 2 shows whether there are significant differences between the groups and the neuropsychological tests performed.

\section{DISCUSSION}

In this study, we evaluated cognitive functions in opioiddependent male patients according to duration of abstinence. We could not find significant differences between patients' values and norm values. When we compared between groups, we found that the group with 0-3 months of abstinence had better long-term memory scores than the others. These results do not support our hypothesis that opioid-dependent patients have worse cognitive functions than healthy people nor that patients with longer abstinence have better cognitive functions.

Patients in the study were divided into 3 groups: abstinent between 0 and 3 months, abstinent between 3 months and 1 year, and abstinent for longer than 1 year. Different intervals were chosen in other studies that evaluated cognitive functions according to the duration of abstinence in opioid addicts. For example, in their 
Table 1: Sociodemographic and clinical characteristics of participants

\begin{tabular}{|c|c|c|c|c|c|c|c|}
\hline & \multicolumn{6}{|c|}{ Duration of Abstinence } & \multirow[b]{3}{*}{$\mathbf{p}$} \\
\hline & \multicolumn{2}{|c|}{$\begin{array}{c}0-3 \text { Months } \\
(n=35)\end{array}$} & \multicolumn{2}{|c|}{$\begin{array}{c}3 \text { Months }-1 \text { Year } \\
(n=31)\end{array}$} & \multicolumn{2}{|c|}{$\begin{array}{l}\text { More than } 1 \text { year } \\
\qquad(n=30)\end{array}$} & \\
\hline & $\mathbf{n}$ & $\%$ & $\mathbf{n}$ & $\%$ & $\mathbf{n}$ & $\%$ & \\
\hline \multicolumn{8}{|l|}{ Marital status } \\
\hline Married & 2 & 5.7 & 5 & 16.1 & 6 & 20 & $0.21^{\mathrm{a}}$ \\
\hline Single & 33 & 94.3 & 26 & 83.9 & 24 & 80 & \\
\hline \multicolumn{8}{|l|}{ Working status } \\
\hline Not working & 23 & 65.7 & 12 & 38.7 & 6 & 20 & $0.01^{b}$ \\
\hline Working & 12 & 34.3 & 19 & 61.3 & 24 & 80 & \\
\hline \multicolumn{8}{|l|}{ Educational status } \\
\hline Middle school & 15 & 42.9 & 15 & 48.4 & 17 & 56.7 & $0.53^{b, 1}$ \\
\hline High school & 18 & 51.4 & 14 & 45.2 & 12 & 40 & \\
\hline University & 2 & 5.7 & 2 & 6.5 & 1 & 3.3 & \\
\hline Age (year) (mean $\pm S D$ ) & 23.37 & 3.34 & 23.55 & 3.12 & 23.20 & 2.56 & 0.905 \\
\hline Monthly income (Turkish Lira) (mean士SD ) & 1615.15 & 1003.78 & 1931.48 & 1862.65 & 1693.33 & 917.24 & 0.630 \\
\hline \multicolumn{8}{|l|}{ First used substance } \\
\hline Cannabis & 30 & 85.7 & 26 & 83.9 & 25 & 83.3 & $0.90^{\mathrm{a}, 2}$ \\
\hline Volatiles & 1 & 2.9 & 1 & 3.2 & 3 & 10 & \\
\hline Heroin & 1 & 2.9 & 4 & 12.9 & 2 & 6.7 & \\
\hline Pills & 1 & 2.9 & 0 & 0 & 0 & 0 & \\
\hline Others & 2 & 5.7 & 0 & 0 & 0 & 0 & \\
\hline \multicolumn{8}{|l|}{ Method of substance use } \\
\hline Inhalation & 30 & 85.7 & 26 & 83.9 & 23 & 76.7 & $0.85^{\mathrm{a}, 3}$ \\
\hline Intravenosis & 5 & 14.3 & 3 & 9.7 & 4 & 13.3 & \\
\hline Others & 0 & 0 & 1 & 3.2 & 0 & 0 & \\
\hline Both intravenosis and inhalation & 0 & 0 & 1 & 3.2 & 3 & 10 & \\
\hline \multicolumn{8}{|l|}{ Frequency } \\
\hline Everyday & 34 & 97.1 & 31 & 100 & 29 & 96.7 & $0.76^{a}$ \\
\hline A few days in a week & 1 & 2.9 & 0 & 0 & 1 & 3.3 & \\
\hline \multicolumn{8}{|l|}{ Treatment } \\
\hline Buprenorphine/naloxone & 23 & 65.7 & 24 & 77.4 & 22 & 73.3 & $0.55^{\mathrm{b}, 4}$ \\
\hline Naltrexone subdermal pellet & 4 & 11.4 & 4 & 12.9 & 2 & 6.7 & \\
\hline Naltrexone oral & 8 & 22.9 & 3 & 9.7 & 6 & 20 & \\
\hline Age of first substance use (year) (mean $\pm S D$ ) & 15.86 & 3.32 & 16.77 & 3.01 & 15.47 & 2.34 & 0.207 \\
\hline Duration of heroin use (months) (mean \pm SD) & 40.46 & 23.21 & 39.29 & 21.57 & 43.8 & 21.15 & 0.710 \\
\hline Number of treatment (mean $\pm S D$ ) & 3.6 & 1.56 & 3.67 & 2.22 & 3 & 1.36 & 0.201 \\
\hline
\end{tabular}

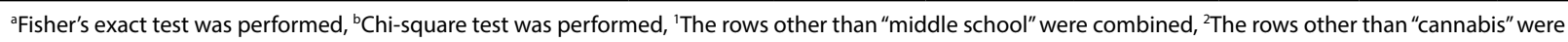
combined, ${ }^{3}$ Only the groups "inhalation" and "intravenosis" were compared, ${ }^{4}$ The groups of "subdermal pellet" and "oral" naltrexone were combined

study on the effect of stress on decision-making, Zhang et al. (26) divided opioid-dependent patients into groups of 3-7-15-30 days and 3-6-12-24 months of abstinence. In 2013, in their studies investigating longterm and short-term decision-making disorders in opioid addicts, Li et al. (12) categorized three groups as short-term (under 6 months), mid-term (6-16 months) and long-term (over 16 months) abstinence. In our study, patients were classed into early remission (between 3 months and 12 months) and continuous remission (over 12 months) according to DSM-5; patients who completed detoxification treatment even if 
Table 2: Comparison of neuropsychological and clinical tests

\begin{tabular}{|c|c|c|c|c|c|c|c|}
\hline Scales & $\begin{array}{l}\text { Source of } \\
\text { variance }\end{array}$ & $\begin{array}{l}\text { Sum of } \\
\text { squares }\end{array}$ & SD & $\begin{array}{l}\text { Averages } \\
\text { of squares }\end{array}$ & $\mathbf{F}$ & $\mathbf{p}$ & Post-hoc \\
\hline \multirow[t]{3}{*}{ BAI } & Intra-group & 1043.75 & 2 & 521.88 & & & \\
\hline & Inter-group & 10168.75 & 93 & 109.34 & 4.773 & 0.011 & $\begin{array}{l}0-3 \text { month }> \\
\text { more than } 1 \text { year }\end{array}$ \\
\hline & Total & 11212.5 & 95 & & & & \\
\hline \multirow[t]{3}{*}{ Stroop test } & Intra-group & 166.68 & 2 & 83.34 & & & \\
\hline & Inter-group & 3606.06 & 93 & 38.78 & 2.149 & 0.122 & - \\
\hline & Total & 3772.74 & 95 & & & & \\
\hline \multicolumn{8}{|l|}{ WCST } \\
\hline \multirow[t]{3}{*}{ Number of total errors } & Intra-group & 39.52 & 2 & 19.76 & & & \\
\hline & Inter-group & 28422.44 & 93 & 305.62 & 0.065 & 0.937 & - \\
\hline & Total & 28461.96 & 95 & & & & \\
\hline \multirow[t]{3}{*}{ Number of categories completed } & Intra-group & 0.13 & 2 & 0.07 & & & \\
\hline & Inter-group & 93.49 & 93 & 1 & 0.067 & 0.936 & - \\
\hline & Total & 93.62 & 95 & & & & \\
\hline \multirow[t]{3}{*}{ Number of perseverative errors } & Intra-group & 130.67 & 2 & 65.33 & & & \\
\hline & Inter-group & 9816.96 & 93 & 105.56 & 0.619 & 0.541 & - \\
\hline & Total & 9947.62 & 95 & & & & \\
\hline \multirow[t]{3}{*}{ Number of non-perseverative errors } & Intra-group & 5.27 & 2 & 2.63 & & & \\
\hline & Inter-group & 8206.69 & 93 & 88.24 & 0.030 & 0.971 & - \\
\hline & Total & 8211.96 & 95 & & & & \\
\hline \multicolumn{8}{|l|}{ AVLT } \\
\hline \multirow[t]{3}{*}{ Short-time memory scores } & Intra-group & 0.84 & 2 & 0.42 & & & \\
\hline & Inter-group & 194.78 & 93 & 2.09 & 0.201 & 0.819 & - \\
\hline & Total & 195.62 & 95 & & & & \\
\hline \multirow[t]{3}{*}{ Auditory-verbal learning scores } & Intra-group & 3.53 & 2 & 1.77 & & & \\
\hline & Inter-group & 307.42 & 93 & 3.31 & 0.535 & 0.588 & - \\
\hline & Total & 310.96 & 95 & & & & \\
\hline \multirow[t]{3}{*}{ Long-term memory scores } & Intra-group & 44.62 & 2 & 22.31 & & & \\
\hline & Inter-group & 657.22 & 93 & 7.07 & 3.157 & 0.047 & $\begin{array}{l}0-3 \text { month }> \\
\text { more than } 1 \text { year }\end{array}$ \\
\hline & Total & 701.83 & 95 & & & & \\
\hline
\end{tabular}

F: One-way analysis of variance, SD: Standard deviation, BAI: Beck Anxiety Inventory, WCST: Wisconsin card sorting test, AVLT: Rey Auditory-verbal learning test

they did not meet early remission criteria and who had not used heroin for at least 14 days were included as a third group. In the other studies, we could not find any criteria for abstinence time. We used DSM-5 to standardize remission criteria. We assumed that if one person is accepted as being in continuous remission, his or her environment, health, nutrition, and social life improve, and all of these affect cognitive tests.

There was no significant difference between the groups by age, socio-economic status (except for employment status), age at onset of substance abuse, duration of multiple substance use, duration of heroin use, and number of treatment referrals $(p>0.05)$. All of these factors influence cognitive functioning and may be confounding factors. In our study, we could eliminate these confounding factors. As quantity and purity of heroin in each pack may vary, the amount of heroin that patients use daily could not be determined clearly in the study. For this reason, the amount of substances used by patients daily is evaluated considering how much substance they were exposed to. Of the patients, $87.5 \%$ reported that they were under the influence of the substance almost every day.

Compared with the norm values in terms of WCST, ST and AVLT, there was no statistically significant difference in any test subscore. 
Studies in the literature comparing opioid dependent with healthy individuals have provided different results. Some authors report that after the toxic effects of opioids have resolved, cognitive functions return to their original state (16-19). On the other hand, some authors suggest that the damage is persistent. For example, in $2013 \mathrm{McDonald}$ et al. (27) found statistically significant differences between the control group (50), non-users who did not receive maintenance treatment (50) and non-users who receive methadone maintenance treatment (125 patient).They evaluated the executive functions, working memory, data processing speed, learning, social perception, and interaction, not finding a significant difference. Darke et al. (28) found that executive functioning, speed of information processing, and maintenance treatment in verbal learning were poor in the study they conducted with 125 older patients who receive maintenance treatment, 50 older users, and 50 healthy controls. They did not find any significant difference in cognitive performance between old users who did not receive maintenance treatment and the control group. The authors assume that even with persistent deterioration, the brain can repair itself, allowing cognitive functions to improve over time. Some authors suggest that opioids lead to persistent cognitive impairment; but there is no clear evidence for which cognitive function is more affected. Whereas some studies suggested that memory was not significantly degraded, it was found to be impaired in numerous other studies $(13,14,29-31)$. While most executive dysfunctions are reported in cognitive functions, results are inconsistent. Some studies have found dysfunction in cognitive flexibility $(29,31)$, others in strategic planning $(13,14,30)$ and again others in decision-making $(18,32)$. The methodological characteristics of the studies make it difficult to generalize the results. For example, some studies were conducted with a very small sample group. Sample sizes of the studies ranged from small groups of 18 patients to samples of more than 100 patients. The number of controlled studies is also very low. Inclusion and exclusion criteria for each study were not clearly defined. Education, age, duration of multiple substance use, age at onset of substance use, head trauma, opioid overdose, and other confounding factors were not controlled in each study. Differences in the tests used to assess cognitive functioning between studies may have led to different results. Our results support studies in which individuals with opioid dependence did not differ from cognitively healthy controls, though this was not consistent with our hypothesis. This can be explained in different ways. In Turkey, heroin is selfadministered in small amounts and purity of the substance is low. Even though patients have been using heroin for a long time, amount and purity of the heroin may not be enough to deteriorate the brain functions. In addition, as has been considered before by several researchers, the effect of the heroin can be transient or the brain may repair itself over time $(16,18,19)$.

When we compared groups within each test, Rey 8 recall scores were higher in the 0-3 months' abstinence group ( $\mathrm{p}=0.047)$. No significant difference was found between the groups in other tests in which cognitive functions were evaluated ( $p>0.05)$.

Memory is one of the basic components of cognitive functions. The AVLT was used in our study to evaluate the short-term and long-term memory and learning. The Rey 8 recall score is associated with long-term memory. Patients with a shorter period of abstinence having better long-term memory may be explained in a number of ways. Although there was no statistically significant difference at first, the education level in the first group was higher. Of the patients in the first group, 20 had high school education and above, while the group abstinent for 1 year and above included 13 graduates from high school or above. The effect of education on cognitive functions is well described in the literature $(14,20,33)$. This may be one of the reasons for the difference between groups. Second, there was a difference in the duration of maintenance treatment among the groups.

All three groups received maintenance treatment with naltrexone or buprenorphine/naloxone. Methadone cannot be prescribed legally in Turkey, so no patient received methadone maintenance treatment. Even though there was no significant difference between the doses of the medicines used by the patients, the group with more than 1 year of abstinence was more likely to have been exposed to these medications for a longer period. The results of studies investigating the effect of maintenance treatment on cognitive functioning in the literature are conflicting. The effect of studies on the cognitive functions of the majority of the medications has been investigated. The nature of the medicines used in maintenance treatment should be noted. Methadone is a full receptor agonist, while buprenorphine is a partial agonist and naltrexone is a full antagonist. It is therefore expected that the effects on cognitive functions of these three drugs will be different. Compared with methadone, buprenorphine and naltrexone are expected to have fewer negative effects on cognitive performance. The number of studies 
investigating the effects of buprenorphine and naltrexone on cognitive performance is limited. It is reported that some of these studies showed positive drug effects. For example, Pirastu et al. (31) found that buprenorphine increased cognitive performance in long-term opioid users. Some studies reported that medicines adversely affected neurocognitive performance. Zacny et al. (34) studied the effects of buprenorphine, morphine, and placebo on psychomotor and cognitive performance in 16 healthy volunteers. Surprisingly, they found that buprenorphine dosedependently leads to impairment in $5 / 6$ of the tests. Memory is also one of the cognitive functions that are impaired in this study. Rapeli et al. (35) prospectively compared buprenorphine/naloxone and methadone in their study of impairment in both groups compared to healthy controls and found that most of the time deterioration persisted in neuropsychological tests. In their study of 38 patients who received buprenorphine treatment, Arias et al. (36) found global neurocognitive impairment in $38 \%$ of patients, and more than one third of patients had impaired learning, memory, executive functions, and verbal fluency. Soyka et al. (37) divided 62 patients with opioid dependence into 2 groups, receiving buprenorphine and methadone treatment, respectively, and compared psychomotor performances at the beginning of treatment and in the 10th week, finding less disruption in the buprenorphine group. In our study, the effect of drugs on neuropsychological tests was not investigated as a primary outcome, but there was no significant difference by medication between the groups. This situation seems to explain why patients complain about forgetfulness while using medication. It is known that conditions such as head trauma, heroin overdose, poor nutrition, and poor physical health also affect cognitive function $(29,38)$. Most of the factors thought to influence cognitive function were not investigated in this study and there was no difference between groups, but head trauma and opioid overdose were not studied. This may be another factor explaining inter-group differences.

Anxiety seen in opioid dependence before the addiction itself may lead to opioid use or it may occur in relation to the toxic effect of the substance due to addiction, withdrawal symptoms, craving or life events. Anxiety levels were found to be significantly higher in the groups with 0-3 months of abstinence compared to the ones who had been abstinent for more than 1 year $(p=0.011)$. Patients often express anxiety symptoms such as internal stress, anxiety, and feeling bad during the detoxification period. This situation is frequently associated with being deprived of the substance, and the subsequent decrease of symptoms supports the idea of anxiety being a symptom of substance withdrawal rather than anxiety disorder. In this study, this can explain the higher anxiety levels of individuals who recently completed detoxification treatment with a 0-3-month abstinence period compared to those who had been abstinent for over one year.

Despite of the large sample group, the large number of tests applied to evaluate different cognitive features, and the exclusion of the toxic effect of heroin, our study has certain limitations:

1. The inclusion of male individuals only limits the generalizability of the study due to the lack of female patients.

2. We compared the study groups against norm values, which have a wide range of variability according to age and educational level. One of the most important limitations is the absence of a control group.

3. There are many factors that affect cognitive functioning. Some factors suggested to affect cognitive functions in individuals with opioid dependence in the literature, such as head trauma and opioid overdose or depression were not included in this study.

4. Most opioid-dependent patients have a past history of multiple substance use. Since the study was not performed with individuals who used opioids as the first and only substance, the results are not generalizable to the effect of opioids alone.

5. All of the patients were admitted to treatment with buprenorphine or naltrexone. Patients receiving buprenorphine were not asked about their compliance with taking daily doses during the test. Although physical withdrawal was not observed, testing was done before patients took their medications, but the possibility of feeling withdrawal symptoms is present, and therefore test performance is likely to be affected.

6. There are conflicting results regarding the effects of drugs used in maintenance treatment on cognitive functions. Patients who received maintenance treatment were included in the study because it was difficult to find any patients who did not receive maintenance treatment.

In this study, in which cognitive functions were evaluated according to the duration of abstinence, no statistically significant deterioration in executive functions, attention, learning, memory, and working memory was found in participants in comparison with the norm values. 
When assessed within the groups, the group with 0-3 months of abstinence was found to have a higher memory scores and anxiety levels compared to the group who had been abstinent for more than 1 year.

This study is very important considering that studies evaluating cognitive functions in opioid dependency are limited; thus, this study contributes to the literature.

Because it is not possible to control all of the factors affecting cognitive functions in opioid dependence, prospective studies assessing the same group of patients cognitively before and after treatment are needed, rather than cross-sectional investigations and animal studies in which the effect of heroin can be examined exclusively.

\begin{tabular}{|c|c|c|}
\hline \multicolumn{2}{|c|}{ Contribution Categories } & \multirow{2}{*}{\begin{tabular}{|l} 
Author Initials \\
B.K., H.A.K., M.H.A., Z.A.
\end{tabular}} \\
\hline \multirow{3}{*}{ Category 1} & Concept/Design & \\
\hline & Data acquisition & C.O.Y., I.V.S. \\
\hline & Data analysis/Interpretation & C.U. \\
\hline \multirow{2}{*}{ Category 2} & Drafting manuscript & H.A.K., M.H.A., C.U., C.O.Y. \\
\hline & Critical revision of manuscript & Z.A., I.V.S., B.K. \\
\hline Category 3 & Final approval and accountability & $\begin{array}{l}\text { B.K., C.O.Y., I.V.S., H.A.K., } \\
\text { M.H.A., C.U., Z.A. }\end{array}$ \\
\hline \multirow{2}{*}{ Other } & Technical or material support & N/A \\
\hline & Supervision & Z.A. \\
\hline
\end{tabular}

Ethics Committee Approval: Approval has been taken from Ethics Committee of Gazi University 10/02/2017; No: 2017-79.

Informed Consent: Written informed consent was obtained from the patient.

Peer-review: Externally peer-reviewed.

Conflict of Interest: No conflict of interest.

Financial Disclosure: No financial support.

\section{REFERENCES}

1. Sadock BJ, Sadock VA, Ruiz P. Kaplan \& Sadock's Synopsis of Psychiatry: Behavioral Science/Clinical Psychiatry. Bozkurt A (Translation Editor) Eleventh ed., Ankara: Gunes Kitabevi, 2016, 659-666. (Turkish)

2. Turkey Drug Report - Data for 2016. Ankara: Turkish Drug and Drug Addiction Monitoring Center, 2017. (Turkish)

3. United Nations Office on Drugs and Crime. World Drug Report 2016. New York: United Nations, 2016.

4. Bukten A, Skurtveit S, Gossop M, Waal H, Stangeland P, Havnes I, et al. Engagement with opioid maintenance treatment and reductions in crime: a longitudinal national cohort study. Addiction 2012; 107:393-399. [CrossRef]

5. Mattick RP, Breen C, Kimber J, Davoli M. Methadone maintenance therapy versus no opioid replacement therapy for opioid dependence. Cochrane Database Syst Rev 2009:CD002209.
6. Lezak MD. Neuropsychological Assessment. Oxford: Oxford University Press, 1995.

7. Pennington BF, Ozonoff S. Executive functions and developmental psychopathology. J Child Psychol Psychiatry 1996; 37:51-87.

8. Ersche KD, Sahakian BJ. The neuropsychology of amphetamine and opiate dependence: implications for treatment. Neuropsychol Rev 2007; 17:317-336. [CrossRef]

9. Baldacchino A, Balfour DJ, Passetti F, Humphris G, Matthews K. Neuropsychological consequences of chronic opioid use: a quantitative review and meta-analysis. Neurosci Biobehav Rev 2012; 36:2056-2068. [CrossRef]

10. Soyka M. Cognitive Functioning in Methadone Use; In Preedy V (editor). Neuropathology of Drug Addictions and Substance Misuse. Amsterdam: Elsevier (Academic Press), 2016, Vol. 3, 603-607. [CrossRef]

11. Fields FR, Fullerton JR. Influence of heroin addiction on neuropsychological functioning. J Consult Clin Psychol 1975; 43:114. [CrossRef]

12. Li X, Zhang F, Zhou Y, Zhang M, Wang X, Shen M. Decisionmaking deficits are still present in heroin abusers after short- to long-term abstinence. Drug Alcohol Depend 2013; 130:61-67.

13. Fishbein DH, Krupitsky E, Flannery BA, Langevin DJ, Bobashev G, Verbitskaya E, et al. Neurocognitive characterizations of Russian heroin addicts without a significant history of other drug use. Drug Alcohol Depend 2007; 90:25-38. [CrossRef]

14. Ornstein TJ, Iddon JL, Baldacchino AM, Sahakian BJ, London M, Everitt BJ, et al. Profiles of cognitive dysfunction in chronic amphetamine and heroin abusers. Neuropsychopharmacology 2000; 23:113-126. [CrossRef]

15. Fernandez-Serrano MJ, Perez-Garcia M, Verdejo-Garcia A. What are the specific vs. generalized effects of drugs of abuse on neuropsychological performance? Neurosci Biobehav Rev 2011; 35:377-406. [CrossRef]

16. Pau CW, Lee TM, Chan SF. The impact of heroin on frontal executive functions. Arch Clin Neuropsychol 2002; 17:663-670.

17. Mintzer MZ, Copersino ML, Stitzer ML. Opioid abuse and cognitive performance. Drug Alcohol Depend 2005; 78:225-230.

18. Verdejo-Garcia AJ, Perales JC, Perez-Garcia M. Cognitive impulsivity in cocaine and heroin polysubstance abusers. Addict Behav 2007; 32:950-966. [CrossRef]

19. Fernandez-Serrano MJ, Perez-Garcia M, Schmidt Rio-Valle J, Verdejo-Garcia A. Neuropsychological consequences of alcohol and drug abuse on different components of executive functions. J Psychopharmacol 2010; 24:1317-1332. [CrossRef]

20. Karakas S, Erdogan E, Dincer Dogutepe E. BIL-NOT YETISKIN: Studies for the Development of Neuropsychological Tests for Adults. Ankara: Egitim Yayinevi, 2013. (Turkish)

21. Beck AT, Epstein N, Brown G, Steer RA. An inventory for measuring clinical anxiety: psychometric properties. J Consult Clin Psychol 1988; 56:893-897. [CrossRef]

22. Ulusoy M, Sahin N, Erkmen H. Turkish version of Beck Anxiety Inventory: psychometric properties. J Cognit Psychother 1998; $12: 163-172$. 
23. Karakas S, Basar E. Standardization of neuropsychological tests in a Turkish sample according to different ages and levels of education. Kriz Dergisi 1993; 159-166. (Turkish)

24. Karakas S, Erdogan E, Sak L, Soysal AS, Ulusoy T, Ulusoy IY, et al. Stroop Test TBAG Form: Standardisation for Turkish Culture, Reliability and Validity. Klinik Psikiyatri Dergisi 1999; 2:75-88. (Turkish)

25. Karakas S, Dogutepe Dincer E. Handbook for the BILNOT Battery: Studies for Research and Development of Neuropsychological Tests for Children (BILNOT COCUK). Ankara: Nobel Tip Kitabevleri, 2011. (Turkish)

26. Zhang XL, Shi J, Zhao LY, Sun LL, Wang J, Wang GB, et al. Effects of stress on decision-making deficits in formerly heroindependent patients after different durations of abstinence. Am J Psychiatry 2011; 168:610-616. [CrossRef]

27. McDonald S, Darke S, Kaye S, Torok M. Deficits in social perception in opioid maintenance patients, abstinent opioid users and non-opioid users. Addiction 2013; 108:566-574.

28. Darke S, McDonald S, Kaye S, Torok M. Comparative patterns of cognitive performance amongst opioid maintenance patients, abstinent opioid users and non-opioid users. Drug Alcohol Depend 2012; 126:309-315. [CrossRef]

29. Darke S, Sims J, McDonald S, Wickes W. Cognitive impairment among methadone maintenance patients. Addiction 2000; 95:687-695. [CrossRef]

30. Ersche KD, Clark L, London M, Robbins TW, Sahakian BJ. Profile of executive and memory function associated with amphetamine and opiate dependence. Neuropsychopharmacology 2006; 31:1036-1047. [CrossRef]

31. Pirastu R, Fais R, Messina M, Bini V, Spiga S, Falconieri D, et al. Impaired decision-making in opiate-dependent subjects: effect of pharmacological therapies. Drug Alcohol Depend 2006; 83:163168. [CrossRef]

32. Brands B, Blake J, Marsh DC, Sproule B, Jeyapalan R, Li S. The impact of benzodiazepine use on methadone maintenance treatment outcomes. J Addict Dis 2008; 27:37-48. [CrossRef]

33. Zeng H, Lee TM, Waters JH, So KF, Sham PC, Schottenfeld RS, et al. Impulsivity, cognitive function, and their relationship in heroin-dependent individuals. J Clin Exp Neuropsychol 2013; 35:897-905. [CrossRef]

34. Zacny JP, Conley K, Galinkin J. Comparing the subjective, psychomotor and physiological effects of intravenous buprenorphine and morphine in healthy volunteers. J Pharmacol Exp Ther 1997; 282:1187-1197.

35. Rapeli P, Fabritius C, Alho H, Salaspuro M, Wahlbeck K, Kalska $\mathrm{H}$. Methadone vs. buprenorphine/naloxone during early opioid substitution treatment: a naturalistic comparison of cognitive performance relative to healthy controls. BMC Clin Pharmacol 2007; 7:5. [CrossRef]

36. Arias F, Arnsten JH, Cunningham CO, Coulehan K, Batchelder A, Brisbane M, et al. Neurocognitive, psychiatric, and substance use characteristics in opioid dependent adults. Addict Behav 2016; 60:137-143. [CrossRef]

37. Soyka M, Hock B, Kagerer S, Lehnert R, Limmer C, Kuefner $\mathrm{H}$. Less impairment on one portion of a driving-relevant psychomotor battery in buprenorphine-maintained than in methadone-maintained patients: results of a randomized clinical trial. J Clin Psychopharmacol 2005; 25:490-493. [CrossRef]

38. Preedy V (editor). Neuropathology of Drug Addictions and Substance Misuse Volume 1: Foundations of Understanding, Tobacco, Alcohol, Cannabinoids and Opioids. Boston: Elsevier, 2016. 